\title{
Desreguladores Endócrinos no Meio Ambiente e o Uso de Potenciais Bioindicadores
}

\author{
Joyce de Araújo Schiavini \\ Universidade Severino Sombra, CECETEN, ex-Discente de \\ Engenharia Ambiental \\ joyceschiavini@hotmail.com \\ Carlos Eduardo Cardoso \\ Universidade Severino Sombra, CECETEN, Química Industrial, \\ Programa de Pós-Graduação em Ciências Ambientais \\ Cardoso221@yahoo.com.br \\ William Costa Rodrigues \\ Universidade Severino Sombra, CECETEN, Engenharia Ambiental, \\ Programa de Pós-Graduação em Ciências Ambientais \\ wcrodrigues@ebras.bio.br
}

\begin{abstract}
Resumo: Os disruptores endócrinos são substâncias que interferem no funcionamento natural do sistema endócrino de homens e animais, estes por sua vez podem ser utilizados como bioindicadores, já que interagem direta ou indiretamente com estas substâncias. O presente trabalho apresenta o estado da arte sobre os desreguladores endócrinos no meio ambiente e o uso potencial de bioindicadores na detecção destas substâncias. A partir dos dados levantados na literatura científica, verifica-se um crescimento no uso de desreguladores endócrinos ao longo do tempo e que os processos de tratamentos dos efluentes contaminados com estas substâncias são incipientes e pouco aplicáveis. Apesar da ampla utilização dos bioindicadores para detecção de substância xenobióticas verifica-se que pouco deles tem resposta direta e precisa dos disruptores endócrinos, permitindo estudos mais aprofundados para aperfeiçoar e selecionar espécies mais eficientes no processo de indicação de alterações de qualidade ambiental.
\end{abstract}

Palavras-chave: Hormônio. Indicadores biológicos. Recurso hídrico. Xenobióticos.

\section{Endocrine Desrupting on Environment and Potential Bioindicators Use}

\begin{abstract}
Endocrine disruptors are substances that interfere with the natural functioning of humans and animals'endocrine system; these, which in turn, can be used as bioindicators, since they directly or indirectly interact with these substances. This paper presents the state of the art on endocrine disrupters in the environment and the potential use of biomarkers in detecting these substances. From the data collected in the scientific literature, there is a growing use of endocrine disruptors over time and that the processes of treatment of effluents
\end{abstract}


contaminated with these substances are very weak and not very applicable. Despite the widespread use of biomarkers for detection of xenobiotics, it is clear that some of them have direct and precise response to endocrine disruptors, allowing further studies to refine and select the most efficient species in the nomination process of changes in environmental quality.

Keywords: Hormone. Biologic indicator. Water resource. Xenobiotic.

\section{Introdução}

Nos últimos 50 anos, alguns compostos sintéticos como os APEOs (etoxilato alquilfenóis) e PCBs (bifenilos policlorados) foram largamente utilizados em variadas aplicações industriais, comerciais e domésticas, sendo parte deles liberados no meio aquático. Alguns destes compostos xenobióticos, presentes em efluentes e lamas industriais, são estrogênicos (tais como o nonilfenol, outros derivados de alquifenóis, PCBs, dietiletoxilados, etc.), e podem induzir alteração nas funções endócrinas de peixes e outros organismos (Santana et al., 2002).

O fluxo dos rios é um recurso renovável que fornece benefícios para os seres humanos, incluindo água para beber, para processos industriais, irrigação, navegação, recreação, eliminação de resíduos, e energia elétrica (Jackson et al., 2001). Todas essas atividades reduzem a qualidade de água e, por conseguinte a biodiversidade aquática (Burgmer et al., 2007).

Segundo Cajaraville et al. (2000) o nível dos compostos xenobióticos nos ecossistemas aquáticos vem crescendo de forma alarmante, nos últimos anos, como resultado da atividade antropogênica sobre o meio ambiente. Contribuindo, desta forma, para a redução da qualidade ambiental, comprometendo a saúde dos seres vivos que habitam esses ecossistemas.

Existe um interesse científico em estudar o fenômeno dos desreguladores endócrinos, já que o assunto vem crescendo, pois os efeitos podem causar danos a saúde de homens e animais. A definição para as substâncias desreguladoras endócrinas ainda não é consensual (Rosa 2008), mas em todas existe um ponto em comum, que é a capacidade de interferir no funcionamento natural do sistema endócrino de homens e animais (Ghiselli e Jardim, 2007).

O desenvolvimento de doenças como câncer de mama, de útero e próstata, desenvolvimento sexual anormal, redução da fertilidade masculina, aumento da incidência de ovários policísticos, distúrbios de fertilização e gravidez anormal são relacionadas à exposição aos desreguladores endócrinos. Essas substâncias também têm potencial para desregular a reprodução e desenvolvimento de animais, além de induzir características sexuais femininas em espécies de peixes machos, podendo levar a esterilização ou redução da população (Ferreira, 2008).

Pesquisas apontam para a redução de anfíbios no mundo todo, sendo que $32 \%$ das espécies estão seriamente ameaçadas e a verdadeira razão para este fato é pouco esclarecida (Stuart et al., 2004). Alguns dos fatores apontados incluem os poluentes químicos (xenobióticos), 
agindo isoladamente ou, ainda, em associação com outros fatores, que incluem modificação e destruição do habitats (Alford e Richards, 1999; Collins e Storfer, 2003).

A rápida urbanização e a expansão das grandes cidades têm resultado, progressivamente, na deterioração das condições de água doce. As bacias hidrográficas urbanas têm sido estudadas para avaliar múltiplos impactos ambientais nessas áreas circundantes. Assim diferentes abordagens têm sido utilizadas em avaliações ambientais, a fim de determinar as condições de deterioração: parâmetros químicos (Meybeck, 1998; Daniel et al., 2002; Lim, 2003).

Quando se trata de bio indicadores, verifica-se que assembleias de macroinvertebrados aquáticos são frequentemente usadas como indicadores da qualidade ambiental, permitindo a detecção e avaliação de impactos nos ecossistemas (Moreno e Callisto 2006). Entretanto, o monitoramento biológico é menos utilizado nos países em desenvolvimento, quando comparado aos desenvolvidos. No entanto, a necessidade da abordagem do biomonitoramento, para avaliar os impactos das atividades humanas sobre os ambientes naturais tem aumentado o número de programas de monitoramento da qualidade da água nos países em desenvolvimento (Castillo et al., 2006; Resh 2007).

O presente trabalho apresenta o estado da arte sobre os desreguladores endócrinos no meio ambiente e o uso potencial de bioindicadores na detecção destas substâncias.

\section{Uso de Recursos Hídricos}

O território brasileiro é constituído de três grandes bacias e de dois complexos de bacias hidrográficas. As três bacias são: a do rio Amazonas, a do rio Tocantins e a do São Francisco, e os dois complexos de Bacias são os do Prata e do Atlântico. O complexo da Bacia do Prata é constituído de três bacias: Alto Paraguai, Paraná e Uruguai e o complexo atlântico é subdividido nos seguintes complexos: Atlântico Norte, Atlântico Nordeste, Atlântico Leste 1, Atlântico Leste 2 e Sudeste (Brasil, 1998).

Segundo Nascimento e Heller (2005) os reflexos das ações de saneamento ou de sua carência são notórios sobre o meio ambiente, e em particular os recursos hídricos. A questão das interfaces entre saneamento e recursos hídricos coloca-se exatamente na dualidade do saneamento como usuário de água e como instrumento de controle de poluição, em consequência, de preservação dos recursos hídricos.

A concentração da população em determinadas regiões, cidades e áreas metropolitanas é um dos principais aspectos a ser considerado na gestão integrada de recursos hídricos, uma vez que implica em demanda tanto por disponibilidade de água para o abastecimento público quanto para dissolução de cargas poluidoras urbanas (Brasil, 1998).

O primeiro passo para a resolução dos problemas sócio-ambientais gerados pela má gestão dos recursos hídricos é o desenvolvimento de metodologias de diagnóstico eficientes (Buss et al., 2003). Ainda segundo os autores, para analisar os aspectos biológicos dos ecossistemas duas metodologias são utilizadas. Os métodos bottom-up utilizam dados de laboratório por meio de experimentação em sistemas simples com extrapolação para sistemas mais complexos. A metodologia top-down avalia, em nível macro, os impactos ambientais por meio da medição da alteração da organização estrutural e funcional das 
comunidades biológicas ou dos ecossistemas.

Estas metodologias permitem uma avaliação mais completa dos impactos no meio hídrico, mas deve ser escolhido de forma adequada, para não gerar problemas na avaliação dos dados obtidos.

\section{Desreguladores Endócrinos}

Existem muitas definições para as substâncias capazes de interferir no sistema endócrino. Entretanto, de acordo com Ghiselli e Jardim (2007) em todas essas definições há um ponto em comum: trata-se de uma substância química que pode interferir no funcionamento natural do sistema endócrino de espécies animais, incluindo os seres humanos. Essas substâncias podem ser de origem antrópica ou natural.

Em inglês, essas substâncias são denominadas Endocrine Disrupting Chemicals (EDC) e alguns autores consideram somente as substâncias que interagem com os sítios receptores de hormônios, embora outros autores considerem como qualquer substância que cause desequilíbrio, interferência ou alteração no sistema endócrino, atuando ou não no sítio receptor (Bila e Dezotti, 2007).

Em seus estudos Ghiselli e Jardim (2007) afirmam que a tradução de endocrine disrupting chemicals tem gerado denominações diferentes, uma vez que o número de pesquisadores brasileiros trabalhando com esse tema, é reduzido comparado com pesquisadores de outros países. Podem ser encontradas as seguintes denominações: "perturbadores endócrinos", "disruptivos ou disruptores endócrinos", "desreguladores endócrinos", "interferentes endócrinos", "estrogênios ambientais".

Segundo Bila e Dezotti (2007) os chamados endocrine disrupting chemicals originalmente foram relacionados com substâncias que mimetizam a ação dos estrogênios naturais, mas com a descoberta de outros mecanismos de ação, houve uma confusão na nomenclatura. Com isso, o que os autores percebem é que a comunidade científica ainda não entrou em consenso sobre qual a nomenclatura correta que deve ser empregada para essa classe de substâncias, no que se refere a todos os seus efeitos causados.

A Comunidade Científica Européia, em 1996, durante a Conferência de Weybridge apresentou uma definição mais precisa e é comumente chamada de definição de Weybridge e diz que: "an endocrine disrupter is an exogenous substance that causes adverse health effects in an intact organism, or its progeny, consequent to changes in endocrine function", ou seja, um disruptor endócrino é uma substância exógena que causa efeitos adversos para a saúde num organismo intacto, ou seus descendentes, devido a mudanças na função endócrina (Ghiselli e Jardim, 2007).

No ano de 1997, segundo Ghiselli e Jardim (2007), a agência de proteção ambiental dos Estados Unidos (U.S. Environmental Protection Agency - USEPA), através do seu comitê consultivo responsável pela avaliação e diagnóstico de interferentes endócrinos (Endocrine Disrupter Screening and Testing Advisory Committee-EDSTAC), apresentou uma definição mais detalhada que considerava os mecanismos envolvidos nas disfunções do sistema endócrino e que tivessem embasamento científico. O EDSTAC descreve um interferente endócrino como uma substância ou mistura química exógena que altera uma ou mais funções do sistema endócrino, bem como a sua estrutura, causando efeitos adversos 
tanto sobre um organismo e sua descendência, como em populações ou subpopulações de organismos, tendo como base estudos científicos, dados, evidências de peso e princípios de precaução.

De acordo com Bila e Dezotti (2007) várias são as substâncias que possuem a capacidade de afetar o sistema endócrino, tais como, substâncias sintéticas (alquilfenóis, pesticidas, ftalatos, policlorados de bifenilas (PCB), bisfenol A, substâncias farmacêuticas, entre outras) e substâncias naturais (estrogênios naturais e fitoestrogênios).

Segundo Reis Filho et al (2006), dentre os hormônios sexuais, os estrógenos vêm recebendo maior atenção por serem compostos extremamente ativos biologicamente e estão relacionados à etiologia de vários tipos de cânceres. Os estrógenos naturais $17 \beta$-estradiol $\left(\mathrm{E}_{2}\right)$, estriol $\left(\mathrm{E}_{3}\right)$, estrona $\left(\mathrm{E}_{1}\right)$ e o sintético $17 \alpha$-etinilestradiol $\left(\mathrm{EE}_{2}\right)$ (Figura 1), desenvolvido para uso médico em terapias de reposição e métodos contraceptivos, são os que despertam maior preocupação, tanto pela potência como pela quantidade contínua introduzida no ambiente. Estes hormônios possuem a melhor conformação reconhecida pelos receptores e, portanto, resultam em respostas máximas, sendo considerados como responsáveis pela maioria dos efeitos disruptores desencadeados pela disposição de efluentes.

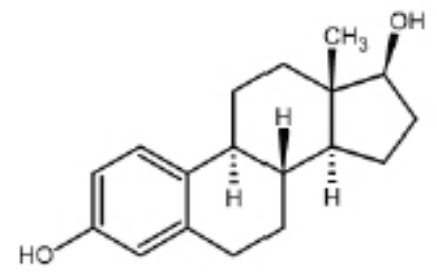

$17 ß-$ Estradio

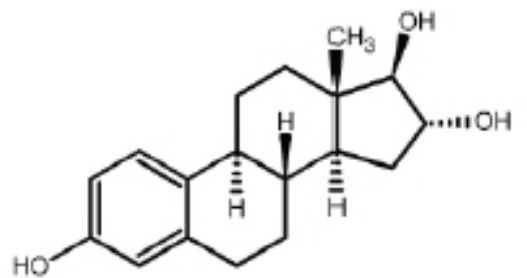

Estriol<smiles>C[C@]12CC[C@@H]3c4ccc(O)cc4CC[C@H]3[C@H]1CCC2=O</smiles>

Estrona

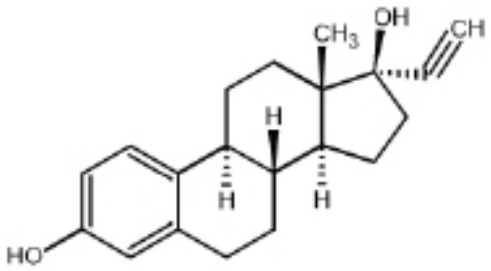

$17 \alpha-$ Etinilestradiol

Figura 1. Estruturas dos principais hormônios estrógenos (Reis Filho et al., 2008).

Em seus estudos Erickson (2002) cita que os hormônios excretados na urina e fezes são levados para a rede coletora, sendo posteriormente levado ao ambiente. O lançamento de efluentes in natura ou mesmo processados são as principais vias de contaminação do ambiente aquático, seja pelo déficit de infraestrutura em saneamento, seja pela ineficiência (tecnológica e/ou operacional) das estações de tratamento. 


\section{Bioindicadores Ambientais}

Alguns moluscos (caramujos e lesmas) que vivem no litoral brasileiro desenvolveram anomalias no sistema reprodutivo resultante da exposição ao TBT(Tributilestanhos). Esses compostos orgânicos contendo estanho, oriundos da tinta dos cascos das embarcações, estão provocando o surgimento de órgãos masculinos em fêmeas, fenômeno conhecido como imposex - imposição sexual - que é irreversível e provoca a esterilização das espécies, podendo causar declínio considerável nas populações de espécies mais sensíveis. Essas substâncias interferem na síntese da testosterona (hormônio masculino), causando um aumento na sua produção nas fêmeas. Essa alteração hormonal faz surgir estruturas sexuais masculinas não funcionais, mantendo-se, porém, a anatomia interna do organismo (Fernandez et al., 2002).

O emprego de uma bateria de bioindicadores abrangendo distintos níveis de organização biológica possibilita o conhecimento sobre a que nível o poluente interage com o organismo, e a que nível este é mais suscetível à ação daquele. Os resultados de trabalhos como este são essenciais para desenhar estratégias eficazes que permitam recuperar a biodiversidade dos ecossistemas aquáticos. A incorporação de Programas de Vigilância e Controle da contaminação ambiental do meio aquático através de uma bateria de bioindicadores proporcionará um conhecimento mais preciso da qualidade ambiental do mesmo (uma vez que permitirá estabelecer o efeito tóxico real que a contaminação exerce sobre as populações). Isto permitirá avaliar e caracterizar o estado de saúde ambiental dos ecossistemas aquáticos, produzindo dados confiáveis que possibilitarão a implementação de medidas adequadas para sua proteção e/ou recuperação, além de permitir a avaliação dos riscos que tais contaminações conferem à Saúde Pública e na biodiversidade desses ecossistemas (Arias et al., 2007).

Para Alford e Richards (1999) muitas espécies de anfíbios ocorrem como metapopulações, de modo à dinâmica das populações locais podem ser pobres indicadores de sua condição. Levando-nos a crer que estas metapopulações são pouco precisas e não devem ser consideradas como indicadores principais, mas devem ser monitoradas.

Os bioindicadores podem ser divididos em dois grupos: de acumulação e de reação (Figura 2). Desta forma, temos os organismos testes, ou seja, são submetidos a ensaios em laboratórios, o que leva a ser bioindicadores ativos, uma vez que há ação e reação direta, por causa e efeito, sem a interferência de atenuadores naturais. Existem também os apontadores, estes permite uma maior precisão das suas respostas, uma vez que haverá interferências dos atenuadores naturais. São bioindicadores passivo, pois necessitam da ação do agente contaminante na dose efetiva, ou próxima a ela, para que ocorra expressão dos efeitos.

A ação de um xenobiótico no organismo desde a exposição do organismo ao poluente, a ação molecular até alteração do ecossistema (Figura 3), o que tem efeito inicial na população diretamente exposta, seguido pela ação em cadeia, principalmente se este xenobiótico for bioacumulador, o mesmo um disruptor endócrino, pois permite alterar o número de indivíduos e reduzindo a oferta de alimento ao nível trófico imediatamente superior. 


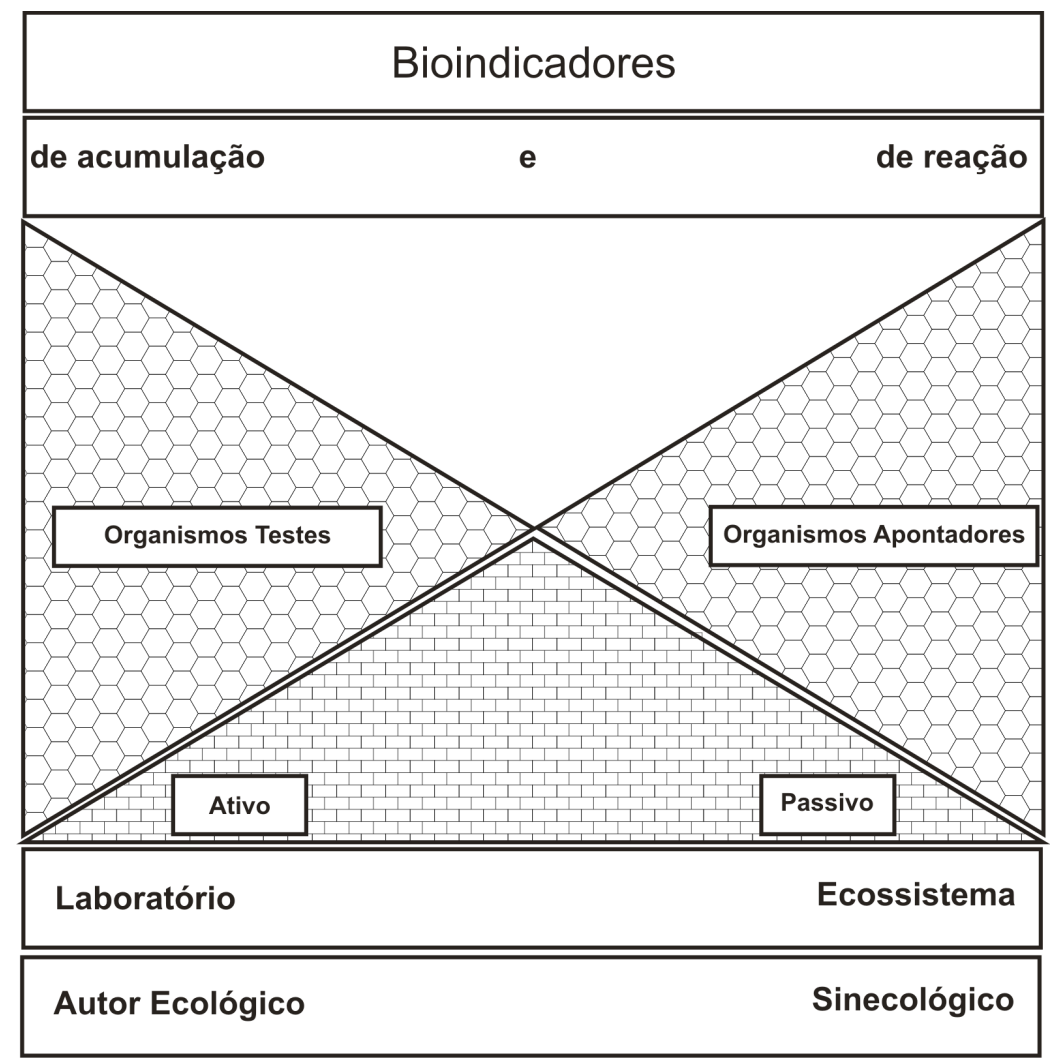

Figura 2. Esquema geral da designação de diferentes formas de uso de bioindicadores (adaptado de Klumpp et al., 2001).

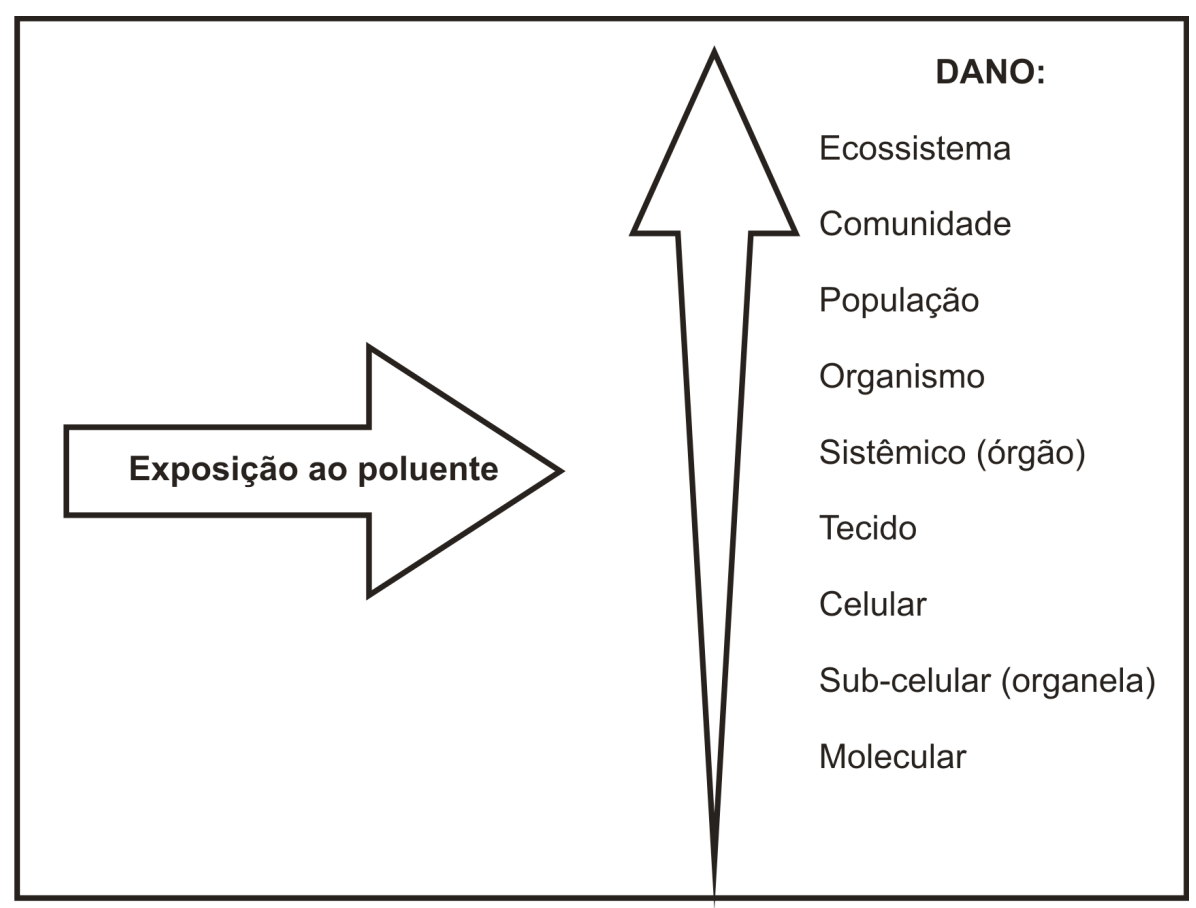

Figura 3. Representação esquemática da ordem sequencial de respostas a poluentes dentro de um sistema biológico (adaptado de Arias et al., 2007). 
No estudo de Thompson et al. (2000) as espécies de peixes Oryzia latipes, Morone saxatalis x Morone chrysops e Ictalurus punctatus foram expostas a concentrações de $17 \beta$-estradiol de 10 a 100 ng.L-1 por 21 dias, ocasionado a indução de vitelogenina no plasma para todas as espécies.

Em seus estudos Arias et al. (2007) usaram como espécies biondicadores acarás (Geophagus brasiliensis) e tilápias (Oreochromis niloticus). Essas espécies foram utilizadas, pois apresentam uma ampla distribuição geográfica e características ecológicas e fisiológicas similares, conhecidas e favoráveis neste tipo de estudo. A tilápia é uma espécie exótica invasora enquanto o acará é autóctona destes ecossistemas, o que torna interessante comparar estas espécies na avaliação do impacto da poluição.

Nos resultados do estudo de Arias et al. (2007) é notório a presença de maiores concentrações de agrotóxicos em Barra Mansa e Paty do Alferes, ambas espécies de peixes, sofrem a ação do inibidores de Acetilcolinesterase (AChE), os autores consideraram, por exemplo, que o uso da bateria de bioindicadores utilizando a comunidade de peixes seja uma metodologia mais adequada para grandes rios, pois estes apresentam, em geral, misturas complexas de poluentes; portanto, a alta especificidade de respostas dos bioindicadores torna-se mais eficiente. Desta forma, independente da origem da espécie, os peixes se mostraram excelentes bioindicadores de níveis de agrotóxicos.

Entre os sistemas testes adequados para o monitoramento da toxicidade, o teste da cebola é conhecido e comumente utilizado em muitos laboratórios de análise (Amaral et al., 2007). A mitose no meristema do ápice radicular de Allium cepa (cebola) foi material pioneiro para estudos de clastogênese; resultado da ação de agentes físicos e químicos, sendo o material introduzido por Levan em 1938 (Fiskesjö 1985).

Em seus estudos Fiskesjö (1985) conclui que as células vegetais normalmente possuem enzimas importantes e necessárias para a ativação de determinadas processos prómutagêneses; este fato foi demonstrado ser o caso das células da ponta da raiz de Allium. Além disso, o teste da cebola combina dois testes alvo: A toxicidade e a mutagenicidade. A toxicidade é facilmente medida pela observação da inibição do crescimento, e, a mutagenicidade está correlacionada com a taxa de rupturas cromossômicas. Assim o risco de eventos mutagênicos pode ser avaliado pela frequência de rupturas cromossômicas induzidas por vários tratamentos. Desta forma, as células da coifa radicular de $A$. cepa constituem um excelente sistema para tais testes citológicos.

Em seus estudos Alvim et al., (2011) concluíram que os efluentes de indústria têxteis analisados promoveram um aumento tanto do índice mitótico como na taxa de anormalidades cromossômicas, demonstrando assim que estes apresentam uma atividade citogenotóxica. Entretanto quando analisado o alongamento de raízes, os autores não verificaram um efeito promotor de crescimento e não foi constatada citotoxicidade. Estando esta explicação pautada na presença dos macronutrientes adicionados e/ou não removidos completamente durante o processo de tratamento biológico empregado, bem como a carga de matéria orgânica em ambas as amostras.

Segundo Bila (2005), o 4-nonilfenol e o bisfenol A foram detectados em águas superficiais de Portugal, na faixa de 0,03 a $30 \mu \mathrm{g} / \mathrm{L}$ e 0,07 a $4,0 \mu \mathrm{g} / \mathrm{L}$, respectivamente. O bisfenol e ftalatos ainda foram encontrados em águas superficiais, sedimentos marinhos, efluentes 
de ETE e lodos biológicos. O que demonstra uma permanência mais prolongada destes compostos no meio ambiente.

Bactérias nitrificantes e outros micro-organismos heterotróficos trabalham em sinergia para a quebra de estrógenos esteróides (Koh et al., 2008). O que além de atuar na degradação, permite utilizá-las como bioindicadores de qualidade ambiental.

No processo de avaliação de risco ecológico a caracterização dos endpoints é a etapa crucial. Neste processo os componentes do ecossistema que podem se adversamente afetados são identificados e a caracterização dos endpoints só é possível a partir do conhecimento dos componentes ecológicos do sistema e de suas inter-relações com os agentes estressores (Hacon 2003). Neste processo devem ser considerados os bioindicadores como "informantes" do estado de alteração ecológica.

Ainda segundo Hacon (2003) essa caracterização permite mensurar repostas biológicas qualitativas em relação aos agentes estressores, as quais podem estar relacionadas ao valor caracterizado como o marcador de endpoint. Esta concentrações permitem definir determinados efeitos adversos em nível de indivíduos e/ou espécies.

Estes bioindicadores permitem verificar as mudanças na concentração de poluentes, alterações no $\mathrm{pH}$ do meio, aumento ou alteração na concentração de sólidos solúveis e sólidos suspensos totais.

Várias espécies vêm sendo empregadas internacionalmente em testes de toxicidade, gerando subsídios importantíssimos para uma melhor avaliação e caracterização dos efeitos agudos e crônicos de diversos agentes tóxicos e em corpos receptores. Dentre eles destacam-se microalgas, microscrustáceos, equinoides, poliquetas, oligoquetas, peixes e bactérias, representando os mais diversos ecossistemas e níveis tróficos (Magalhães e Ferrão Filho, 2008).

\section{Ação de Desreguladores Endócrinos no Ambiente}

Muitos desreguladores endócrinos competem com o estradiol (hormônio sexual feminino produzido naturalmente pelo organismo) pelos receptores de estrogênio. Outros competem com a diidrotestosterona (hormônio sexual masculino produzido naturalmente pelo organismo) pelos receptores de androgênio. Por isso, estas substâncias têm a capacidade de produzir efeitos de feminização (substâncias estrogênicas) ou masculinização (substâncias androgênicas) sobre o sistema endócrino. (Lintelmann et al., 2003). Como alguns animais possuem o sistema reprodutivo, inclusive sistema hormonal similar ao dos seres humanos as ações são verificadas na fauna silvestre.

Os efeitos que são desencadeados pela exposição às substâncias desreguladoras do sistema endócrino no ambiente são percebidos em microinvertebrados até grandes vertebrados e ultimamente tem sido relatado na literatura científica como uma questão de âmbito global (Reis Filho et al., 2006).

Assim que um efluente é lançado, a dispersão e o transporte das várias substâncias que o contaminam são dependentes tanto das propriedades físicas e químicas do meio receptor quanto das próprias características das substâncias disponibilizadas (Servos et al. 1996, apud Reis Filho et al., 2007). 
Segundo Reis Filho et al., (2007) predizer o destino e a exposição da biota aquática aos contaminantes em razão da dinâmica do meio e da ampla diversidade de estruturas químicas existentes nos efluentes é ponto crítico em estudos ambientais. Além dos efeitos sobre os organismos e suas populações, podem surgir efeitos sobre todo o ecossistema atingido. Esses efeitos ocorrem devido às interações existentes entre os organismos e o seu meio e, dessa forma, sua real extensão sobre os organismos pode ser descrita como "ecossistema-dependente" (Connell e Miller, 1984 apud Reis Filho et al., 2007).

A ocorrência de desreguladores endócrinos presentes no meio ambiente é bastante relatada em estudos, principalmente no meio aquático, em águas superficiais e de subsolo, sedimentos marinhos, efluentes e lodos biológicos de estações de tratamento de efluentes e água potável. As concentrações dessas substâncias são relevantes e podem afetar a qualidade da água, a saúde dos ecossistemas e impactar o suprimento de água potável (Bila e Dezotti, 2007).

Nas estações de tratamento de esgoto da Alemanha, Inglaterra, Holanda e Estados Unidos, as concentrações médias de $17 \alpha$-etinilestradiol em efluentes domésticos na esteve na faixa de 1 a 3 ng/L aproximadamente ou abaixo do limite de detecção. Apesar das concentrações serem baixas, elas são de extrema importância para o ambiente aquático, levando em conta que atividades estrogênicas in vitro mostraram que a exposição de peixes a uma concentração de somente $0,1 \mathrm{ng} / \mathrm{L}$ de $17 \alpha$-etinilestradiol pode provocar feminização de machos de algumas espécies (Ferreira, 2008).

\section{Avaliação de Resíduos de Desreguladores}

Os métodos analíticos tradicionais capazes de avaliar pesticidas organofosforados e carbamatos em água são realizados por cromatografia gasosa (GC), cromatografia líquida de alta performance (HPLC) ou espectofotometria de massa (MS) (Lacorte e Barcelo 1995).

Devido à dificuldade de identificação desses micropoluentes no meio ambiente, muitos métodos analíticos foram desenvolvidos para detectar e quantificar essas substâncias em matrizes ambientais complexas, tais como águas superficiais e subterrâneas, esgoto doméstico, efluentes de ETE, sedimentos marinhos, solo e lodo biológico. Adicionalmente, a necessidade de se conhecer os efeitos potenciais dos desreguladores endócrinos tem conduzido a uma demanda por métodos de ensaios in vitro e in vivo para identificar os efeitos biológicos de uma grande variedade de substâncias naturais e sintéticas presentes no meio ambiente (Bila e Dezotti, 2007).

\section{Tratamentos Aplicados na Remoção de Desreguladores Endócrinos}

A partir de seus estudos Koh et al., (2008), conclui que estrogênios esteróides são excretados a partir do corpo em grandes quantidades e podem chegar ao ambiente aquático, em concentrações de até ng/L, portanto, a constante descarga e persistência, exige que a atenção seja focada em sua remoção ou desativação endócrinas, no tratamento de esgoto. Os autores concluem ainda, que os processos de tratamento físico-químico, pode servir como etapas de anterior ao tratamento biológico, pode produzir uma queda adicional de 
hormônios no efluente águas residuais, a níveis ultra-baixos, no entanto os seus custos e praticabilidade requer otimização.

Os processos oxidativos avançados são bastante eficientes na degradação de substâncias orgânicas e que possam estar em baixas concentrações (Ferreira, 2008). Nesses processos são geralmente usados combinações de agentes oxidantes $\left(\mathrm{H}_{2} \mathrm{O}_{2}\right.$ ou $\left.\mathrm{O}_{3}\right)$, irradiação (UV e ultrasom) e catalisadores (íons metálicos e fotocatalisadores) (Bila 2005). Os processos mais comumente usados são $\mathrm{O}_{3} / \mathrm{H}_{2} \mathrm{O}_{2}, \mathrm{O}_{3} / \mathrm{UV}, \mathrm{H}_{2} \mathrm{O}_{2} / \mathrm{UV}$, ozônio em $\mathrm{pH}$ básico e fotocatálise com $\mathrm{TiO}_{2}$ (Tabela 1) (Ferreira, 2008). Esses processos são aplicados no tratamento de águas subterrâneas, redução de excesso de lodo biológico de ETE, e compostos orgânicos voláteis. O número de aplicação dos POA em tratamento de água tem aumentado devido à oportunidade de remoção dos precursores dos subprodutos de desinfecção, remoção de micropoluentes (fármacos, desreguladores endócrinos e biotoxinas) e inativação de micro-organismos patogênicos resistentes. Esses processos podem ser acompanhados de outros, sejam biológicos ou físico-químicos, a fim de obter melhor desempenho e eficiência do tratamento (Bila, 2005).

Tabela 1. Remoção de estrogênio por alguns processos oxidativos avançados, comumente usados, segundo Ferreira (2008).

\begin{tabular}{|c|c|c|c|}
\hline Estrogênio & Matriz & Processo & Resultado \\
\hline $17 \beta$-estradiol & Água Mili-Q & Foto-Fenton & $\begin{array}{l}\text { O processo de foto-Fenton foi capaz de remover } \\
86,4 \% \text { de } 17 \beta \text {-estradiol após } 8 \mathrm{~h} \text { de reação, } \\
\text { enquanto que o processo de Fenton removeu } \\
\text { apenas } 40,1 \% \text {. }\end{array}$ \\
\hline Estrona - $17 \beta$-estradiol & $\begin{array}{l}\text { Água } \\
\text { Ultrapura }\end{array}$ & $\begin{array}{l}\text { Fotocatálise } \\
\text { com } \mathrm{TiO}_{2}\end{array}$ & $\begin{array}{l}\text { No reator com lâmpada de } 150 \mathrm{~W}, 97 \% \text { das } \\
\text { substâncias foram degradadas com } 4 \mathrm{~h} \text { de } \\
\text { irradiação. No reator com lâmpada de } 15 \mathrm{~W} \text {, } \\
98 \% \text { das substâncias desapareceram com } 1 \mathrm{~h} \text { de } \\
\text { tratamento, devido à menor faixa de comprimento } \\
\text { de onda da lâmpada de UV (fixada a } 253 \mathrm{~nm} \text { ) }\end{array}$ \\
\hline $\begin{array}{c}\text { 17ß-estradiol } \\
\text { Bisfenol A }\end{array}$ & Água & $\begin{array}{l}\text { O3 } \\
\text { O3/UV }\end{array}$ & $\begin{array}{l}\text { O3/UV possibilitou remoção igual ao processo } \\
\text { de O3 com diminuição de } 22,5 \% \text { no consumo de } \\
\text { O3. }\end{array}$ \\
\hline $\begin{array}{c}17 \beta \text {-estradiol } \\
17 \alpha \text {-etinilestradiol estriol }\end{array}$ & Água & $\begin{array}{l}\text { Fotocatálise } \\
\text { Fotólise }\end{array}$ & $\begin{array}{l}\text { Fotocatálise e fotólise foram capazes de degradar } \\
\text { os três compostos. A fotocatálise mostrou-se mais } \\
\text { efetiva que a fotólise. O 17a-etinilestradiol foi } \\
\text { degradado primeiramente devido à tripla ligação } \\
\text { que absorve a luz UV mais facilmente. }\end{array}$ \\
\hline
\end{tabular}




\section{Considerações Finais}

Sendo os disruptores endócrinos substâncias que interferem no funcionamento natural do sistema endócrino de homens e animais verifica-se preocupação abaixo do esperado, no que se refere ao poder público em qualquer instância em alterar a legislação regulando e restringindo o uso de diversas substâncias. Principalmente, porque estas substâncias são bastante relatadas em estudos demonstrando claramente os malefícios a saúde humana, animal e ao ambiente de forma geral.

Verifica-se ao longo do tempo um crescimento no uso de desreguladores (disruptores) endócrinos e os processos de tratamentos dos efluentes contaminados com estas substâncias são incipientes e pouco aplicáveis, devido a alto custo e baixa eficiência em parte destes processos, obviamente os que possuem maior eficiência tendem a serem mais caros, o que inviabiliza, sob o ponto de vistas econômico a sua implantação em curto prazo.

Apesar da ampla utilização dos bioindicadores para detecção de substância xenobióticas verifica-se que pouco deles tem resposta direta e precisa aos disruptores endócrinos, cabendo estudos mais aprofundados para aperfeiçoar e selecionar espécies mais eficientes no processo de indicação de alterações de qualidade ambiental.

Experimentos publicados na literatura científica, verifica-se que o teste da cebola, possui características desejáveis ao processo de monitoramento ambiental, destacando o baixo custo, a resposta rápida, resposta a pequenas variações do meio e eficiência na avaliação comparativa entre ambientes contaminados de forma mais severa, e menos severas, tomando como padrão a água potável. 


\section{Referências}

Alford, A.R.; Richards, J.R. (1999) Global Amphibian Declines: a problem in applied ecology. Annual Review of Ecology and Systematics. 30:133-165.

Alvim, L. B.; Kummrow, F.; Beijo, L. A; Lima, C. A. de A.; Barbosa, S. (2011) Avaliação da citogenotoxicidade de efluentes têxteis utilizando Allium cepa L.. Ambi-Agua, 6: 255-265.

Amaral, A.M, Barbério, A., Voltolini, J.C. e Barros, L. (2007). Avaliação preliminar da citotoxicidade e genotoxicidade, da água da bacia do rio Tapanhon (SP-Brasil) através do teste Allium (Allium cepa). Revista Brasileira de Toxicologia, 20: 65-72.

Arias, A.R.L, Buss, D.F., Alburquerque, C., Inácio, A.F., Freire, M.M., Egler, M., Mugnai, R. e Baptista, D.F. (2007). Utilização de bioindicadores na avaliação de impacto e no monitoramento da contaminação de rios e córregos por agrotóxicos. Ciência \& Saúde Coletiva. 12: 61-72.

Bila, D.M. e Dezotti, M. (2007). Desreguladores endócrinos no meio ambiente: efeitos e conseqüências. Química Nova, 30: 651-666.

Bila, D.M. (2005). Degradação e remoção da atividade estrogênica do desregulador endócrino 17 $\beta$-estradiol pelo processo de ozonização. Universidade Federal do Rio de Janeiro/ COPPE. Tese de doutorado, 281p.

Brasil (1998). Recursos hídricos no Brasil. Ministério do Meio Ambiente, dos Recursos Hídricos e da Amazônia Legal: Secretaria de Recursos Hídricos. 33p.

Burgmer, T., Hillebrand, H. e Pfenninger, M. (2007). Effects of climate-driven temperature changes on the diversity of freshwater macroinvertebrates. Oecologia 151: 93-103.

Buss, D.F., Baptista, D.F. e Nessimian, J.L. (2003). Bases conceituais para a aplicação de biomonitoramento em programas de avaliação da qualidade da água de rios. Caderno de Saúde Pública. 19: 465-473.

Cajaraville M.P., Bebianno, J.M., Blasco J., Porte, C., Sarasquete, C. e Viarengo, A. (2000). The use of biomarkers to assess the impact of pollution in coastal environments of the Iberian Peninsula: a practical approach. Science of the Total Environment. 247:295311.

Castillo, L.E., Martínez, E., Ruepert, C., Savage, C., Gilek, M., Pinnock, M. e Solis, E. (2006). Water quality and macroinvertebrate community response following pesticide applications in a banana plantation, Limon, Costa Rica. Science of the Total Environment. 367: 418-432.

Collins, J.P. e Storfer, A. (2003) Global amphibian declines: sorting the hypotheses. Diversity and Distributions, 9:89-98.

Daniel, M.H.B., Montebelo, A.A., Bernardes, M.C., Ometto, J.P.H.B., Camargo, P.B., Krusche, A.V., Ballester, M.V., Victoria, R.L. e Martinelli, L.A. (2002). Effects of urban sewage on dissolved oxygen, dissolved inorganic and organic carbon, and electrical conductivity of small streams along a gradient of urbanization in the piracicaba river basin. Water, Air, and Soil Pollution. 136: 189-206.

Erickson B.E. (2002). Analyzing the ignored environmental contaminants. Environmental Science \& Technology, 36:140A-5A. 
Fernandez, M.A., Limaverde, A.M., Castro, I.B., Almeida, A.C.M. e Wagener, A.L.R. (2002). Occurrence of imposex in Thais haemastoma: possible evidence of environmental contamination derived from organotin compounds in Rio de Janeiro and Fortaleza, Brazil. Caderno de Saúde Pública. 18: 463-476.

Ferreira, M.G.M. (2008). Remoção da atividade estrogênica de $17 \beta$-estradiol e de $17 \alpha$-etinilestradiol pelos processos de ozonização e $\mathrm{O}_{3} / \mathrm{H}_{2} \mathrm{O}_{2}$. Tese de Doutorado, $173 p$.

Ghiselli, G. e Jardim, W.F.(2007). Interferentes endócrinos no ambiente. Química Nova, 30: 695-706.

Hacon, S.S. (2003) Avaliação e gestão do risco ecotoxicológico à saúde humana. p 246322. In: Azevedo, F.A. e Chasin, A.A.M. (Coordenadores). As bases Ecotoxicológicas da Ecotoxicologia. Rima/Intertox: São Paulo. 322p.

Jackson, R.B., Carpenter, S.R., Dahm, C.N., McKnight, D.M., Naiman, R.J., Postel, S.L. e Running, S.W. (2001). Water in a changing world. Ecological Applications. 11: 1027-1045.

Klumpp, A., Wolfgang, A., Klumpp, G. e Fomin, A. (2001). Um novo conceito de monitoramento e comunicação ambiental: a rede europeia para a avaliação da qualidade do ar usando plantas bioindicadoras (EuroBionet). Revista Brasileira de Botânica. 24: $511-518$

Koh, Y.K.K., Chiu, T.Y., Boobis, A., Cartmell, E., Scrimshaw, M.D. e Lester, J.N. (2008). Treatment and removal strategies for estrogens from wastewater. Environmental Technology, 29, 245-267.

Lacorte, S. e Barcelo, D. (1995) Determination of organophosphorus pesticides and their transformation products in river water by automated on-line solid-phase extraction followed by thermospray liquid chromatography-mass spectrometry. Journal of Chromatography A.712: 103-112.

Lim, H.S. (2003). Variations in the water quality of a small urban tropical catchment: implications for load estimation and water quality monitoring. Hydrobiologia. 494: 57-63.

Lintelmann, J., Katayama, A., Kurihara, N., Shore, L. e Wenzell, A. (2003). Endocrine Disruptors in the environment (IUPAC TECHNICAL REPORT). Pure and Applied Chemistry, 75: 631-682.

Magalhães, D.P. e Ferrão Filho, A.S. (2008). A Ecotoxicologia como ferramenta no biomonitoramento d eecossistemas aquáticos. Oecologia Brasiliensis. 12: 355-381.

Meybeck, M. (1998). Man and river interface: multiple impacts on water and particulates chemistry illustrated in the Seine river basin. Hydrobiologia. 373: 1-20.

Moreno, P. e Callisto, M. (2006). Benthic macroinvertebrates in the watershed of an urban reservoir in southeastern Brazil. Hydrobiologia. 560: 311-321.

Reis Filho, R.W., Araújo, J.C. e Vieira, E.M. (2006). Hormônios sexuais estrógenos: contaminantes bioativos. Química Nova, 29: 817-822.

Reis Filho, R.W., Luvizotto-Santos, R. e Vieira, E.M. (2007). Poluentes Emergentes como Desreguladores Endócrinos. Journal of the Brazilian Society of Ecotoxicology, 2: $283-288$. 
Resh, V.H. (2007). Multinational, freshwater biomonitoring programs in the developing world: lessons learned from African and Southeast Asian river surveys. Environmental Management. 39: 737-748.

Rosa, R.M.R. (2008). Contribuição para o estudo de Compostos Desreguladores Endócrinos (EDC) em estações de tratamento de águas residuais (ETAR): estudo da remoção de EDC'S numa ETAR com tratamento terciário. Universidade Nova de Lisboa. Tese de Mestrado. 143p.

Santana, F., Muelle, H., Mateus, E. e Sepúlveda (2002). Avaliação de impactos da aplicação no solo de compostos disruptores endócrinos. p. 15-26 In: Duarte, A., Santos, T.R., Panteleitchouk, A. e Prego, R. Ecotoxicologia e Remoção de Poluentes: Estudos na Península Ibérica. Coleção Estudos e Documentos. Instituto Piaget: Lisboa, 252p.

Stuart, S.N., Chanson, J.S., Cox, N.A., Young, B.E., Rodrigues, A.S.L., Fischman, D.L. and Waller, R.W. (2004). Status and trends of amphibian declines and extinctions worldwide. Science. 306: 1783-1786.

Thompson, S., Tilton, F., Schlenk, D. e Benson W.H. (2000). Comparative Vitellogenic Responses in Three Teleost Species: Extrapolation to in Situ Feld Studies. Marine Environmental Research, 51: 185-189. 